\title{
1006 ローラーコースターの運動と振動に関する座標系の扱いの影響 Dynamic Behavior of A Moving Body on 3-D Trajectory
}

\author{
○学 船越裕二(阪府大院) 正 藤田勝久 (阪府大) 学 渡邊頌子（阪府大）
}

Yuji FUNAKOSHI, Mechanical Systems Engineering, Graduate school of Engineering, Osaka Pref. Univ. 1-1 Gakuen-cho, Sakai, Osaka, 599-8531, Katsuhisa FUJITA, Osaka Pref. Univ. NOBUKO Watanabe, Osaka Pref. Univ.

\begin{abstract}
Dynamics of a moving body restrained on a 3-D trajectory considering resistance to forward motion is investigated. The equation of motion of the moving body is derived by using differential algebraic equations (DAE). By using this equation, the time history simulation analysis is performed. Also, the kinematics and vibratical experiment have been performed using the actual roller coaster in site. The accelerations in simulation are compared to those in experiment. Both show a good coincidence qualitatively.
\end{abstract}

Key Words: multi-body dynamics, moving body, 3D trajectory, DAE, roller coaster

\section{1 緒言}

近年, 輸送産業技術の発展により, 遊戯施設の開発も 進んでいる。.これに伴いローラーコースター(以下， RC とする)においても高速化や軌道の複雑化が求められてお り，安全性，または乗り心地を考える上で、その動的举 動解析が重要になってきている。本研究では, RCを 3 次 元軌道上に拘束された移動体としてとらえ，その動的举 動解析を行うことを考元る. その手法として、3 次元軌道 上に拘束される移動体の質点を仮想質点とし、車両質点 と仮想質点とをバネ・ダンパーで結んだモデルの運動方 程式を導出し、拘束条件と連立させ、乗客にかかる動的 举動のシミュレーションを行う。また、シミュレーション 值と実测值を比較し、アルゴリズムの妥当性を検討する。

\section{2 座標軸の定義}

Fig.1に示す座標系を考える．まず、固定座楣として絶 対座標系 $x_{g}-y_{g}-z_{g}$ を定義する。RCの軌道は、この 座椤系に拘束されている。次に、 RC の軌道を $x_{g}-y_{g}$ 平 面に射影した軌道上に、進行方向が正となるように $s$ 軸 をとり、 $z_{g}$ 軸と同じ方向に $z$ 軸をとり、 $s-z$ 平面に直交 する方向を $u$ 軸とした座摆系を $s-u-z$ 座檡系とする。 また、 RC の軌道上で進行方向を正とした接線方向の軸 を $x_{l}$ 軸、垂直な方向に $z_{l}$ 軸、 $x_{l}-z_{l}$ 平面に直交するよ うに $y_{l}$ 軸をとつた座檡系を局所座樏系 $x_{l}-y_{l}-z_{l}$ とす る。なお、 $y_{l}$ 回りの回転角をピッチ角 $\alpha[\mathrm{rad}] 、 x_{l}$ 軸回り の回転角をカント角 $\beta[\mathrm{rad}] 、 z_{l}$ 軸まわりの回転角をヨー 角 $\gamma[\mathrm{rad}]$ とする。 $\mathrm{RC}$ の軌道は絶対座椤系 $x_{g}-y_{g}-z_{g}$ に 拘束されているとする。ピッチ角 $\alpha$ は上りを正とし、力 ント角 $\beta, \exists$ 一角 $\gamma$ は左回りを正とする。

\section{3 車両モデル}

Fig.2 に示すように車両を 3 次元でモテル化した．レー ルとタイヤの接点を仮想的に質量を与え，この質点の質量 を $m_{0}$ とする．また，タイヤ，キャビン，フレーム，乗客 などの質点の質量を $m_{i}(i=1 \sim n)$ とし, 各方向 $x_{l}, y_{l}, z_{l}$ 方向にバネ定数 $k_{n}$ ，堿衰係数 $c_{n}$ の線形バネ・ダンバ要 素で置き換える．今回は数值解析を簡単にするため仮想 質点 $m_{0}$ と，その他フレーム，乗客などを合わせた質点 $m_{1}$ の2質点系で解析を行っている. RCのタイヤとサス ペンションは自動車のそれらよりはるかに硬い。そのた め自由度を表す程度として単純なモテルで十分である。

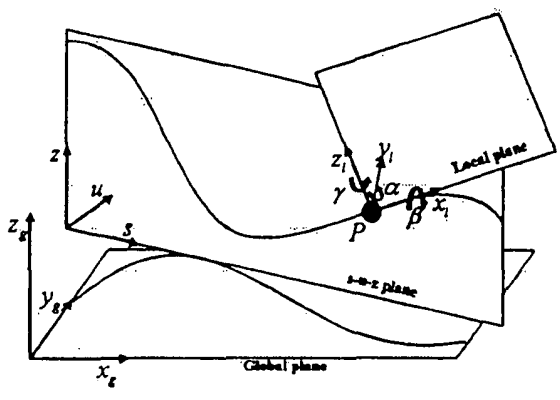

Fig. 1: definition of plane

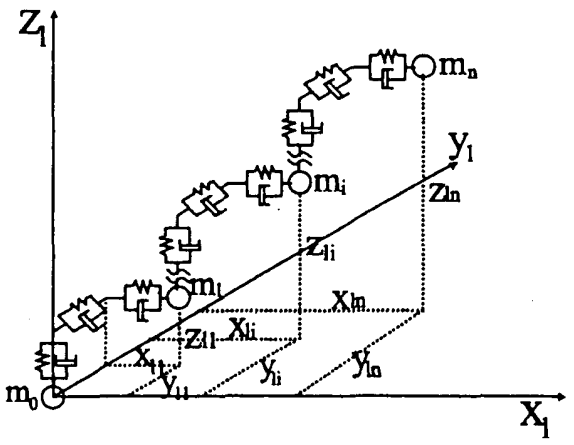

c) simulation model

Fig. 2: Modeling of a vehicle

\section{4 解析理論}

Fig.1 に示す $s-z$ 平面で解析を行う場合, $s, z$ 方向の 非拘束時の運動方程式を導出し， $u$ 軸方向は遠心力より求 める. 次に， $s, u, z$ 方向の拘束条件之連立させ，得られた 加速度に回転座標変換を行い，実験值と同等の加速度を 得る.ここでは, 絶対座檡系 $x_{g}-y_{g}-z_{g}$ (Fig.1参照) で 表畋された軌道に拘束されて運動する質点の $x_{g}-y_{g}-z_{g}$ 方向の運動方程式を導出する手法を述べる．絶対座檡系 を移動する仮想質点 $m_{0}$ の $x_{g}, y_{g}, z_{g}$ 方向の運動方程式は 次式によって得られる。

$$
\left[M_{x y z 0}\right]\left\{\ddot{q}_{x y z 0}\right\}=[T]\left\{f_{l 1}\right\}+\left[M_{x y z 0}\right]\left\{G_{x y z}\right\}
$$


ここで。 $\left\{\ddot{q}_{x y z 0}\right\}=[\ddot{x}, \ddot{y}, \ddot{z}]^{T}$,

$\left[M_{x y z 0}\right]=\operatorname{diag}\left(m_{0}, m_{0}, m_{0}\right),\left\{G_{x y z}\right\}=[0,0,-g]^{T}$ とし, $g$ は重力加速度とする. 絶対座標系で求的ること他より 3 軸方向同時に求めることができる.ここで用いている回 転マトリクス $T$ は。 $x_{l}-y_{l}-z_{l}$ 座標系から $x_{g}-y_{g}-z_{g}$ 座檈系に変換する座檡変換行列である. Fig.1より,その とき回転マトリクス $T$ は次式のようになる.

$$
[T]=\left[T_{\alpha}\right]\left[T_{\beta}\right]\left[T_{\gamma}\right]
$$

また，仮想質点 $m_{0}$ の拘束条件を次式のように表す.

$$
\left\{\Phi_{x y z 0}\left\{q_{x y z 0}\right\}\right\}=0
$$

次に、Fig.2に示されている車両質点について、非拘束 時の運動方程式を導出する。まず，質点 $m_{i}$ に惐く外力 $\left\{F_{x y z i}\right\}$ は次のように構成されていると考えられる.

(a) 重力項

車両はそれ自身にエンジンは付いていないので，重力に よって動いている. それゆえ，質点 $m_{i}$ にかかる重力項は 次式のようになる.

$$
\left\{f_{x y z i}^{(g)}\right\}=\left[M_{i}\right]\{G\}
$$

ここで, $\left[M_{i}\right]=\operatorname{diag}\left[m_{i}, m_{i}, m_{i}\right],\{G\}=[0,0,-g]^{T}$ とす る.

(b) 瞵接している質点にかかる外力

略接する質点 $m_{i-1}, m_{i+1}$ によって受ける質点 $m_{i}$ の外力 は次のように表せる。

$$
\begin{aligned}
& \left\{f_{x y z i}^{(C)}\right\}=[T]\left[C_{i}\right]\left[\dot{q}_{l(i-1)}^{T}, \dot{q}_{l i}^{T}, \dot{q}_{l(i+1)}^{T}\right]^{T} \\
& \left\{f_{x y z i}^{(K)}\right\}=[T]\left[K_{i}\right]\left[q_{l(i-1)}^{T}, q_{l i}^{T}, q_{l(i+1)}^{T}\right]^{T}
\end{aligned}
$$

ここで。 $\left[C_{i}\right],\left[K_{i}\right]$ は $x_{l}-y_{l}-z_{l}$ 座祭系での質点 $m_{i}$ に対

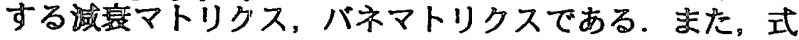
(1) で用いられている $\left\{f_{61}\right\}$ はこれらを用いると次式のよ うに表せる。

$$
\left\{f_{l 1}\right\}=\left[C_{1}\right]\left\{\dot{q}_{l 1}\right\}+\left[K_{1}\right]\left\{q_{l 1}\right\}
$$

よって絶対座祭系を移動する質点 $m_{1} \sim m_{n}$ の $x_{g}, y_{g}, z_{g}$ 方 向の運動方程式は次式のようになる.

$$
\begin{aligned}
& {\left[M_{v}\right]\left\{\ddot{q}_{x y z v}\right\}=\left\{F_{x y z v}\right\}} \\
& \text { ここで, }\left[M_{v}\right]=\left[\begin{array}{ccc}
m_{1} & & 0 \\
& \ldots & \\
0 & & m_{n}
\end{array}\right] \\
& \left\{q_{x y z v}\right\}=\left[\left\{q_{x y z 1}\right\}^{T} \cdots\left\{q_{x y z n}\right\}^{T}\right]^{T} .
\end{aligned}
$$

また, 質点 $m_{1} \sim m_{n}$ についての拘束条件は次式のように なる。

$$
\left\{\Phi_{x y z v}\left(\left\{q_{x y z v}\right\}\right)\right\}=0
$$

式 (1)，(3)，(8)，(9)を連立させると，質点 $m_{0}, m_{1} \sim m_{n}$ に対する変位ベクトル $q_{x y z}$ を省くことができる，そのと きの混合微分代数方程式は次のようになる.

$$
\begin{aligned}
& {\left[\begin{array}{cc}
M & \frac{\partial \Phi_{x y z}}{\partial q_{x y z}} \\
\frac{\partial \Phi_{x y z}}{\partial q_{x y z}} & 0
\end{array}\right]\left\{\begin{array}{c}
\ddot{q}_{x y z} \\
\lambda
\end{array}\right\}=\left[\begin{array}{c}
\mathbb{P}_{x y z} \\
-\frac{\partial}{\partial q_{z y z}}\left(\frac{\partial \beta}{\partial q_{x y z}} \dot{q}_{x y z}\right) \dot{q}_{x y z}
\end{array}\right]} \\
& こ こ て ゙,\left\{q_{x y z}\right\}=\left[\left\{q_{x y z}\right\}^{T},\left\{q_{x y z v}\right\}^{T}\right]^{T} \\
& \left\{\Phi_{x y z}\right\}=\left[\left\{\Phi_{x y z}\right\}^{T},\left\{\Phi_{x y z v}\right\}^{T}\right]^{T}
\end{aligned}
$$

$$
\begin{aligned}
{[M] } & =\left[\begin{array}{cc}
M_{0} & 0 \\
0 & M_{v}
\end{array}\right]_{\left\{F_{x y z}\right\}}=\left[\left\{F_{x y z 0}\right\}^{T},\left\{F_{x y z v}\right\}^{T}\right]^{T} .
\end{aligned}
$$

式 (10) を $\ddot{q}_{x y z}$ について解くと, $x_{g}, y_{g}, z_{g}$ 方向の加速度 が次式のように得られる。

$$
\left\{\ddot{q}_{x y z}\right\}=\left[\left\{\ddot{q}_{x y z 0}\right\}^{T},\left\{\ddot{q}_{x y z v}\right\}^{T}\right]^{T}
$$

式 (11) の加速度に回転座標変換を行うと, 実際の車両で 計測した実駼值と同等の加速度が得られる.

\section{5 実験結果と解析結果}

Fig.3 は, 実際の RC の車両の床に加速度計を取り付 けて RC を走行させ，そのときの 3 方向, $x_{l}, y_{l}, z_{l}$ の計测 した加速度応答の時刻歴波形を示している. また，Fig.4 は s-z 平面での解析結果を示している.
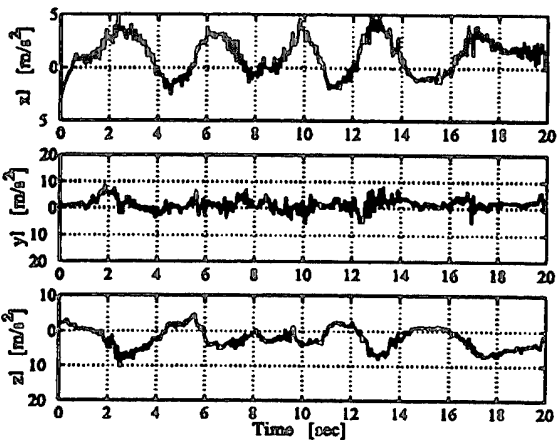

Fig. 3: Measured vibration response of an actual roller coaster filtered by $10 \mathrm{~Hz}$
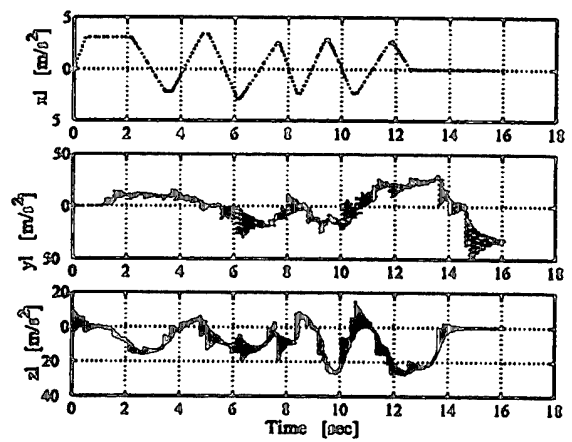

Fig. 4: simuretion analysis of s-z plane

\section{参洁文塥}

1) E.J.Haug, Allyn and Bacon (1989).

2) K.Fujita, T.Kimura, Y.Yamamoto, Proc. of the 2001 ASME Design Engineering Technical Conference and Computers and Information in Engineering Conferences, VIB-21337 in CD-ROM.

3) K.Fujita, Y.Uemura, Y.Funakoshi, Y.Yamamoto, Proc. of the First Asian Conference on Multibody Dynamics 2002, Iwaki, Fukushima, Japan (2002). 